\title{
Commentary: To see, you need the cee-tee!
}

\author{
Ross M. Bremner, MD, PhD
}

\author{
From the Norton Thoracic Institute, St Joseph's Hospital and Medical Center, Phoenix, Ariz. \\ Disclosures: Author has nothing to disclose with regard to commercial support. \\ Received for publication Jan 2, 2019; accepted for publication Jan 2, 2019; available ahead of print Feb 7, 2019 \\ Address for reprints: Ross M. Bremner, MD, PhD, Norton Thoracic Institute, St Joseph's Hospital and Medical \\ Center, 500 W Thomas Rd, Suite 500, Phoenix, AZ 85013 (E-mail: Ross.Bremner@ DignityHealth.org). \\ J Thorac Cardiovasc Surg 2019;157:1719 \\ $0022-5223 / \$ 36.00$ \\ Copyright $(C) 2019$ by The American Association for Thoracic Surgery \\ https://doi.org/10.1016/j.jtcvs.2019.01.001
}

In this issue of the Journal, Gauthier and colleagues ${ }^{1}$ have reviewed the use of chest computed tomography (CT) in donor evaluation before acceptance of an organ for implantation. It is a retrospective study, but the data have been carefully evaluated. They noted that $74.9 \%$ of donors had undergone CT at some point during the lung evaluation, and that the finding of structural lung disease on CT negatively affected the decision to use the organ.

In this age of prolific CT use, it is perhaps surprising that CT is not routinely used to evaluate all lungs for potential donation. It is clearly far superior to chest radiography as a method of evaluating lung parenchyma, and CT adds significantly to the information that can be used in the decision-making process. We have not yet studied how specific CT findings in donors affect recipient outcomes, however, and it is unfortunate that the current study of Gauthier and colleagues ${ }^{1}$ does not begin to shine light on this essential question. On the one hand, CT findings may dissuade a center from taking certain organs, when in fact they may have performed quite well; on the other, CT findings may result in organs being turned down appropriately, because findings such as severe emphysema or lung cancer are likely to portend a poor outcome. The cost of a CT scan of the chest is minimal compared with the cost of flying to a donor site, where structural lung disease or a lung nodule suggestive of cancer may result in a so-called "dry run." At my institution, the cost of a noncontrast CT scan is less than $\$ 80$ and, apart from transport to the CT scanner, takes very little time.

It is also perhaps surprising that data on the donor (such as the original CT images) are not routinely prospectively collected by all organ procurement organizations in collaboration with transplant centers, because these data could help us learn how to improve long-term lung transplant outcomes. As pointed out by Gauthier and colleagues, ${ }^{1}$ we still only have a 5-year survival of 54\% in lung transplantation. This low rate is primarily related to the high incidence of chronic rejection, of which one of the main determinants is the degree of primary graft dysfunction early in the

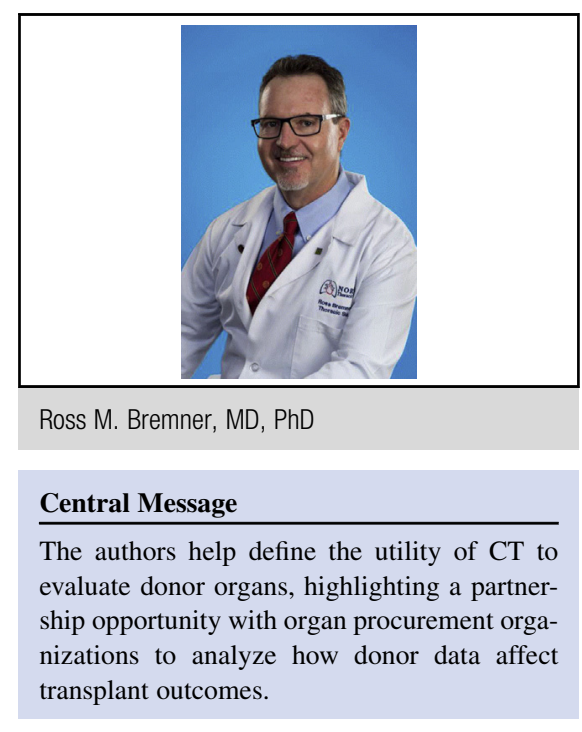

See Article page 1711.

postimplantation period. We should be asking several important questions. What degree of contusion in traumatic lung injury, or what degree of consolidation in pneumonia, is related to a high risk of primary graft dysfunction? What degrees are, in fact, acceptable? Alternatively, can we accept mild emphysematous changes if the recipient is critically ill and cannot wait for a "more perfect" lung? As we know, recipient factors also play into the decision-making process of donor acceptance.

The science of long-term outcomes in lung transplantation is still imperfect, partly because there are so many elements that influence both primary graft dysfunction and chronic rejection. Gauthier and colleagues ${ }^{1}$ are to be applauded for their efforts to help us define the use of CT to evaluate donor organs, and this article adds to the call that CT should be done routinely on all lung donors (as echocardiograms and catheterization are in heart donors). This article also highlights the great opportunity to partner with our organ procurement organizations to collect data (including CT imaging) about donors prospectively and to analyze these data in relation to short- and long-term transplant outcomes.

\section{Reference}

1. Gauthier JM, Bierhals AJ, Liu J, Balsara KR, Frederiksen C, Gremminger E, et al Chest CT imaging improves potential lung donor assessment. J Thorac Cardiovasc Surg. 2019;157:1711-8.e1. 